\title{
La incertidumbre en la apertura de los servicios de cirugía ambulatoria en Colombia
}

\author{
Uncertainty in the opening of ambulatory surgery services in Colombia \\ Carlos E. Díaz-Castrillón (D)
}

Médico, Especialista en Cirugía General, Pontificia Universidad Javeriana, Bogotá DC., Colombia

Recibimos con grata satisfacción el esfuerzo de la Asociación Colombiana de Cirugía para estandarizar las pautas de manejo en los servicios quirúrgicos durante la pandemia de COVID-I9. Su participación en los comunicados de las sociedades científicas, la promoción de la educación continuada por medios digitales y la creación de una edición especial en esta revista para condensar las contribuciones desde varias partes de Colombia sobre el tema ', son muestra del liderazgo y la capacidad de resiliencia de los cirujanos en momentos de crisis.

Es fácil concebir las distintas perspectivas sanitarias, éticas y económicas que justifican reabrir los servicios quirúrgicos ambulatorios y, a su vez, es evidente la necesidad de adaptar nuestra práctica clínica a las nuevas pautas de la situación excepcional. Con la voluntad de adaptación evidenciada en la Encuesta de percepción sobre el impacto de la pandemia ${ }^{2}$, los diferentes actores de los servicios de cirugía estamos dispuestos para retornar al quirófano, bajo los nuevos estándares.

En la última entrega colectiva del grupo de trabajo Cirugía-ACC-Covid-I9 ${ }^{3}$, los autores hacen una revisión de las múltiples consideraciones para reiniciar los servicios de cirugía ambulatoria en Colombia, de lo cual resalto la forma exhaustiva y concisa como se abarcaron los diferentes dominios que esta nueva fase operacional implica. En tiempos donde nos enfrentamos a una condición nueva y dinámica, el establecimiento de rutas de trabajo es fundamental para ofrecer un servicio seguro mientras se optimiza el uso de los recursos disponibles. Tras observar que los objetivos planteados en el documento se cumplieron a cabalidad, persiste el debate sobre la incertidumbre alrededor de la evaluación del riesgo de infección en pacientes asintomáticos y la baja confiabilidad en la estimación de la prevalencia de la enfermedad en la población general.

Palabras clave: COVID-I9; virus del SRAS; infecciones por coronavirus; diagnóstico; pandemias; cirugía general.

Key words: COVID-I9; SARS virus; coronavirus infections; diagnosis; pandemics; general surgery.

Fecha de recibido: 18/05/2020 - Fecha de aceptación: 22/05/2020

Autor de correspondencia: Carlos Eduardo Díaz-Castrillón, M.D. Faculty Pavilion-Fifth Floor, 4401 Penn Avenue, Pittsburgh, PA 15224. Teléfono: (+1) 412-580-3204. Correo electrónico: cediazc@gmail.com

Citar como: Díaz-Castrillón CE. La incertidumbre en la apertura de los servicios de cirugía ambulatoria en Colombia. Rev Colomb Cir. 2020;35:526-8. https://doi.org/10-30944/20117582.732

Este es un artículo de acceso abierto bajo una Licencia Creative Commons - BY-NC-ND https://creativecommons.org/licenses/by-ncnd/4.0/deed.es 
En primer lugar, es importante aclarar que el uso de las herramientas de tamización clínica tiene poco valor predictivo en la valoración del riesgo de infección en los pacientes asintomáticos y, por lo tanto, es impreciso correlacionar estos instrumentos de medición con las pruebas de laboratorio. La consideración de factores sociodemográficos adicionales, tales como lugar de residencia y la exposición a lugares o personas de alto riesgo, entre otros, son de mayor utilidad en este grupo de pacientes. Este es uno de los mayores retos que conlleva el ejercicio de decidir quién es apto para ser llevado a cirugía de forma segura en un escenario en el que aproximadamente el 30\% de las personas infectadas permanecerá asintomáticas ${ }^{4,5}$.

Es cierto que las pruebas basadas en anticuerpos son un recurso útil para determinar la historia infecciosa de personas asintomáticas y estimar la prevalencia de la enfermedad. También es cierto, como bien señalan los autores, que las características operativas de las diferentes pruebas disponibles son muy variables $y$, además, dependientes de las probabilidades pretest. Aunque el uso de estas pruebas se ha enfocado en la identificación de pacientes de alto riesgo con pruebas moleculares negativas ${ }^{6}$, se ha demostrado que la probabilidad de falsos negativos depende a su vez de la severidad de la enfermedad ${ }^{7}$ y que pueden presentar reactividad cruzada con otro tipo de coronavirus ${ }^{8}$. No obstante, la mayor desventaja seguirá siendo su incapacidad para descartar una infección activa cuando aún no haya seroconversión, sabiendo que se empieza a detectar IgM a partir del cuarto día de iniciados los síntomas ${ }^{9}$ y que, además, la probabilidad de falsos negativos de las pruebas moleculares puede variar del Ioo $\%$ al $66 \%$ durante los primeros 4 días de infección ${ }^{\mathrm{I}}$.

En segundo lugar, la estimación de la prevalencia de la enfermedad en Colombia presenta

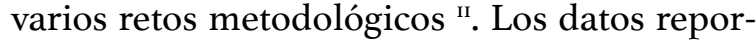
tados por el Instituto Nacional de Salud son el resultado de un muestreo selectivo en pacientes sintomáticos, lo cual es una representación imperfecta del estado real de la pandemia. Hasta la fecha no se cuenta con datos derivados de la población general, en donde estimaciones por medio de muestreo probabilístico serían una aproximación más cercana a la realidad. En todo caso, esta medición configuraría una prevalencia de punto en el marco de una enfermedad altamente cambiante. Por ejemplo, en el mes de abril, un estudio aleatorio en la ciudad de Nueva York mostró un $20 \%$ de seropositividad en la muestra estudiada, dato que para el día de hoy puede ser una subestimación. Tendremos que esperar el estudio anunciado por la Universidad de los Andes y la Universidad Nacional, quienes proponen una metodología similar para dar algún lineamiento al respecto ${ }^{12}$. Esta es una iniciativa valiosa que debería ser secundada por más instituciones académicas en Colombia.

Alrededor de las consideraciones mencionadas persisten algunos interrogantes: ¿Cómo saber cuándo se ha llegado al umbral de implementación de pruebas serológicas en todos los pacientes? ¿Se tiene certeza de no infección con una prueba serológica negativa? ¿Es necesario que los hospitales realicen estudios piloto mediante pruebas directas en todos los pacientes que van a ser llevados a procedimientos quirúrgicos?

Ante la ausencia de una respuesta clara y desconociendo la costo-efectividad de combinar pruebas serológicas y moleculares en nuestro medio, debemos entonces balancear este riesgo con la utilización de varias estrategias en paralelo, como la priorización de los pacientes según el riesgo epidemiológico local, el mantenimiento del distanciamiento social, la educación de los pacientes, la implementación de programas de seguimiento estrictos previo a la cirugía y el uso estricto de elementos de protección personal, como bien lo indican los autores. La alta variabilidad del estado de la pandemia y de los recursos disponibles en Colombia obliga a cada institución a determinar cuál es la mejor estrategia por implementar para la reapertura de los servicios ambulatorios. Finalmente, es de suma importancia recalcar que es indispensable la participación directa de los pacientes con decisiones informadas sobre el riesgo que se está asumiendo. 


\section{Referencias}

I. Bejarano M. Especial COVID-I9. Rev Colomb Cir. 2020;35:I40. https://doi.org/I0.30944/20II7582.604

2. Diaz-Castrillon CE, Cortes M, Rey S, Pineda M, Diaz-Castrillon J, Sierra S. Percepción de la pandemia COVID-I9 en los servicios de cirugía en Colombia. Rev Colomb Cirugía. 2020;35:290-30I. https://doi.org/I0.30944/20117582.655

3. Barrios A, Prieto RG, Torregrosa L, Álvarez CA, Hernández-Restrepo JD, González LG, et al. Volver a empezar: cirugía electiva durante la pandemia del SARS-CoV2. Recomendaciones desde la Asociación Colombiana de Cirugía. Rev Colomb Cir. 2020;35: 302-2I.

https://doi.org/I0.30944/20II7582.656

4. Kimball A, Hatfield KM, Arons M, James A, Taylor J, Spicer K, et al. Asymptomatic and presymptomatic SARS-CoV-2 infections in residents of a long-term care skilled nursing facility - King County, Washington, March 2020. MMWR Morb Mortal Wkly Rep. 2020;69:377-8I. Disponible en: http://www.cdc. gov/mmwr/volumes/69/wr/mm69I3eI.htm?s_cid=mm69izeI_W

5. Linton NM, Kobayashi T, Yang Y, Hayashi K, Akhmetzhanov AR, Jung S, et al. Incubation period and other epidemiological characteristics of 2019 novel coronavirus infections with right truncation: A statistical analysis of publicly available case data. J Clin Med. 2020;9:538. Disponible en:

https://www.mdpi.com/2077-0383/9/2/538

6. Zhong L, Chuan J, Gong B, Shuai P, Zhou Y, Zhang Y, et al. Detection of serum IgM and IgG for COVID-I9 diagnosis. Sci China Life Sci. 2020;63:777-80. Disponible en: http://link.springer.com/IO.IOO7/sII427-02O-I688-9
7. Lee CY-P, Lin RTP, Renia L, Ng LFP. Serological approaches for COVID-I9: Epidemiologic perspective on surveillance and control. Front Immunol. 2020 Apr 24;II. Disponible en: https://www.frontiersin.org/article/ı0.3389/fimmu.2020.00879/full

8. Petherick A. Developing antibody tests for SARS-CoV-2. Lancet. 2020;395:IIOI-2. Disponible en: https://linkinghub.elsevier.com/retrieve/pii/SoI4067362030788I

9. Zhao R, Li M, Song H, Chen J, Ren W, Feng Y, et al. Early detection of SARS-CoV-2 antibodies in COVID-I9 patients as a serologic marker of infection. Clin Infect Dis. 2020 May I; Disponible en: https://academic.oup. com/cid/advance-article/doi/Io.I093/cid/ciaa523/5827750

Io. Kucirka L, Lauer S, Laeyendecker O, Boon D, Lessler J. Variation in false negative rate of RT-PCR based SARSCoV-2 tests by time since exposure. medRxiv. 2020 Jan I;2020.04.07.2005I474. Disponible en: http://medrxiv. org/content/early/2020/04/IO/2020.04.07.2005I474. abstract

II. Lu FS, Nguyen AT, Link N, Santillana M. Estimating the prevalence of COVID-I9 in the United States: Three complementary approaches. medRxiv. 2020 Jan I;2020.04.I8.2007082I. Disponible en: http://medrxiv.org/content/early/2020/04/23/2020.04.18.2007082I. abstract

I2. EL Tiempo. Universidad de los Andes busca datos sociodemográficos del COVID-I9. El Tiempo. 2020. Disponible en: https://www.eltiempo.com/bogota/ universidad-de-los-andes-busca-datos-sociodemograficos-de-la-covid-19-486838 